\title{
A case of arteriovenous malformation of the nasal dorsum
}

\author{
Hyejeen Kim, MD ${ }^{1} \mathbb{1 0}$, Jung Myung Kim, $\mathrm{MD}^{2} \mathbb{D}$, Ji Yun Choi, MD, PhD ${ }^{1}$ \\ 'Department of Otolaryngology-Head and Neck Surgery, Chosun University College of Medicine, Gwangju, Rep. of Korea \\ ${ }^{2}$ Department of Radiology, Chosun University College of Medicine, Gwangju, Rep. of Korea
}

\begin{abstract}
Arteriovenous malformation (AVM) is a vascular malformation with an abnormal capillary shunt between the arterial and venous systems. AVMs can arise anywhere on the body, and are occasionally located in the head and neck. However, AVMs of the nose are considerably rare. Most cases of AVMs of the nose have no symptoms, but some cases show epistaxis and nasal obstruction. Furthermore, a differential diagnosis between hemangioma, lymphangioma, and AVM is important. In cases of AVMs, especially on the face, surgeons should consider cosmetic factors and choose an appropriate plan of treatment. We report the case of a 22-yearold male who presented with an asymptomatic, palpable mass on the nasal dorsum and was successfully treated with transcatheter arterial embolization and sclerotherapy.
\end{abstract}

Keywords: arteriovenous malformations; embolization; nasal dorsum; sclerotherapy

\section{Introduction}

Arteriovenous malformation (AVM) is a vascular malformation with an abnormal capillary shunt between the arterial and venous systems. Mostly, AVMs are congenital malformations, but are clinically relevant later in life and are frequently diagnosed at around 19 years of age with no sex-related association $[1,2]$. AVMs can arise in any part of the body; they are commonly located in the head and neck region and rarely in the nose [3].

Hence, this report presents the case of an AVM on the nasal dorsum, which was treated with transcatheter arterial embolization and sclerotherapy.

\section{Case report}

A 22-year-old male presented with a palpable mass on the nasal dorsum. He accidentally found the mass and had symptoms of right-sided nasal obstruction and occasional headaches. Physical examination revealed a mass on the nasal dorsum approximately $1 \mathrm{~cm} \times 1 \mathrm{~cm}$ in size (Fig. 1). On sinus endoscopy, right-sided nasal septum deviation and watery rhinorrhea was observed on both sides. On computed tomography of the paranasal sinuses, a lobulated mass, approximately $11 \mathrm{~mm}$ in size, with well-defined margins, and hyperenhancement was observed on the right nasal dorsum. The mass was enhanced to the same degree as the vascular lesion; therefore, we assumed that the lesion could be a hemangioma or vascular malformation (Fig. 2).

We performed a diagnostic angiography to diagnose the lesion. The vessels were accessed through the right common femoral artery. On angiography through the external carotid artery, we found a rapidly filling vascular mass and venous drain-

Received June 7, 2021; Revised June 10, 2021; Accepted June 10, 2021

Corresponding author: Ji Yun Choi

E-mail: happyent@naver.com

This is an Open Access article distributed under the terms of the Creative Commons Attribution Non-Commercial License (http://creativecommons.org/licenses/by-nc/4.0), which permits unrestricted non-commercial use, distribution, and reproduction in any medium, provided the original work is properly cited.

Copyright (C) 2021 Korean Society of Korean Cosmetic Surgery and Medicine (KSKCS \& KCCS). 
age on the right nasal dorsum. We confirmed that the mass was fed through the lateral nasal branch of the facial artery. Through left-sided angiography, we confirmed that there was no venous flow on the left side and no feeding artery or drainage (Fig. 3). Therefore, we concluded that the mass might be an arteriovascular malformation, not a hemangioma.

We could not locate the mass using sinus endoscopy. The patient complained of symptoms of nasal obstruction and wanted to undergo septoplasty and turbinoplasty. Before surgery, we
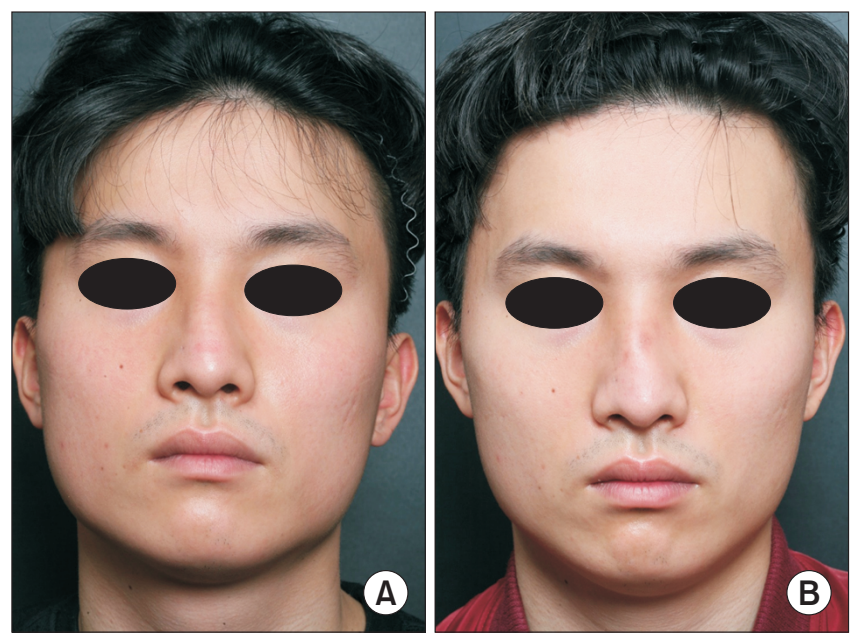

Fig. 1. (A) Pretreatment photograph showing protruding and pulsating mass on the right nasal dorsum. (B) Posttreatment photograph showing no visible mass on the nasal dorsum. performed intravascular embolization for the arteriovascular malformations. Under local anesthesia, with the right femoral artery catheter, we accessed the vessels and confirmed the lateral nasal artery from the facial artery. Particle embolization was performed using a microcatheter on the proximal part of the lateral nasal artery with three separate micro-coils. After completing the procedure, we confirmed that there were no more vessels feeding the mass using angiography through the right external carotid artery (Fig. 4). Similarly, with left-sided external carotid artery angiography, we confirmed that there was no vessels feeding the mass (Fig. 5).
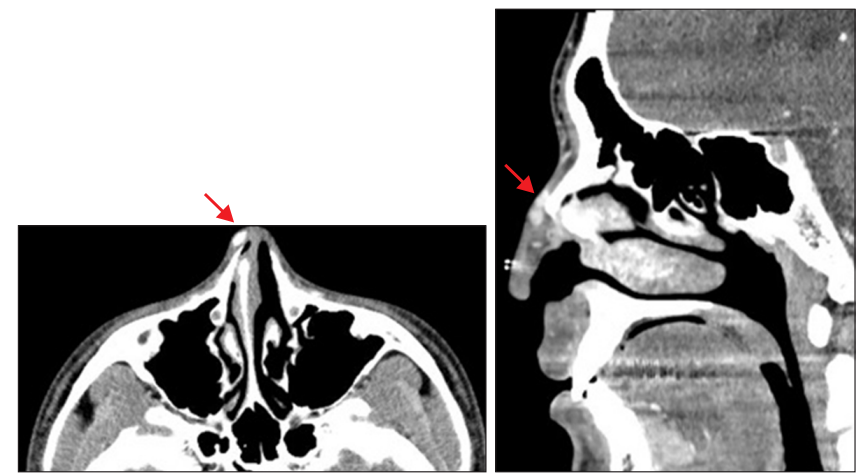

Fig. 2. Computed tomography of the paranasal sinuses shows an 11mm lobulated mass (arrows) with well-defined margins enhanced on the right nasal dorsum. The enhancement of the mass was similar to that of a vascular lesion; therefore, we deduced that it could be a hemangioma or vascular malformation.
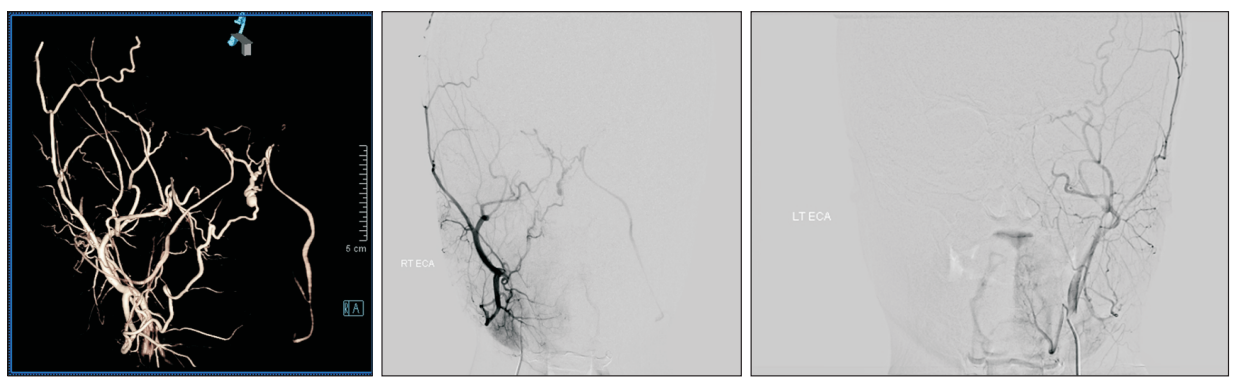

Fig. 3. Diagnostic angiography. On angiogram through external carotid artery, a rapidly filling vascular mass with venous drainage was observed on the right nasal dorsum. We confirmed that the mass was being fed through the lateral nasal branch of the facial artery.
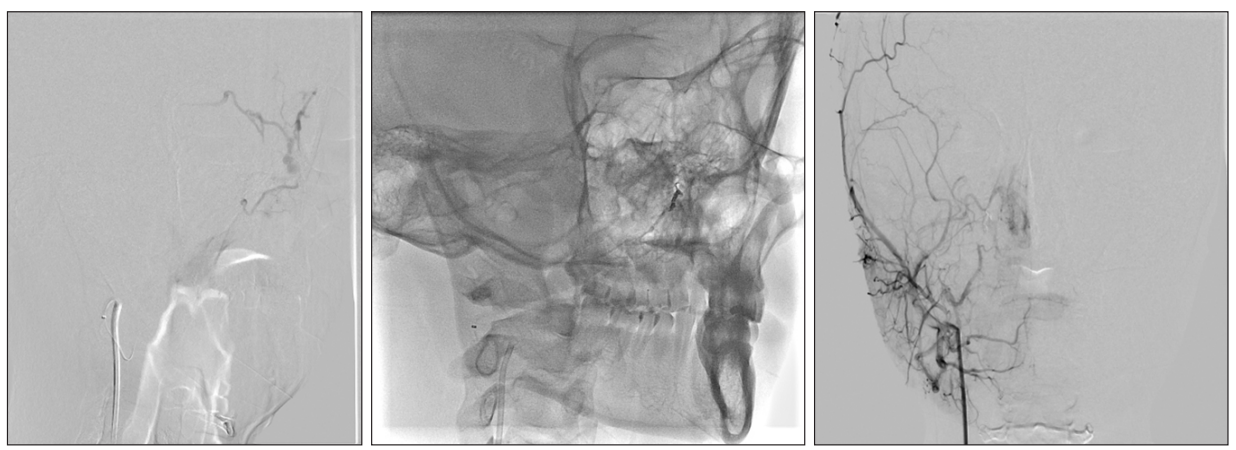

Fig. 4. We performed particle embolization with a microcatheter and three separate micro-coils on the proximal part of the lateral nasal artery. 

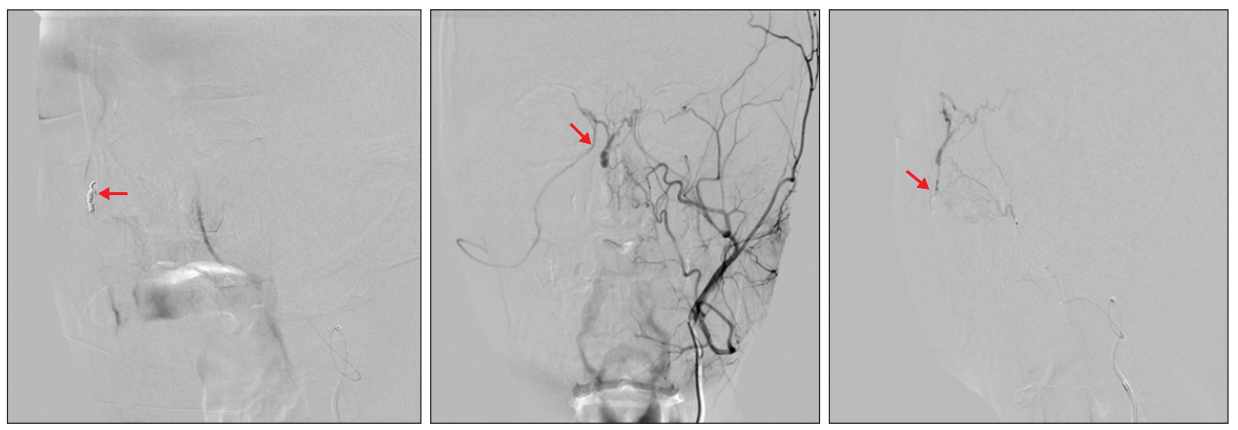

Fig. 5. With left-sided external carotid artery angiography, we confirmed that there were no vessels to feed the mass (arrows).
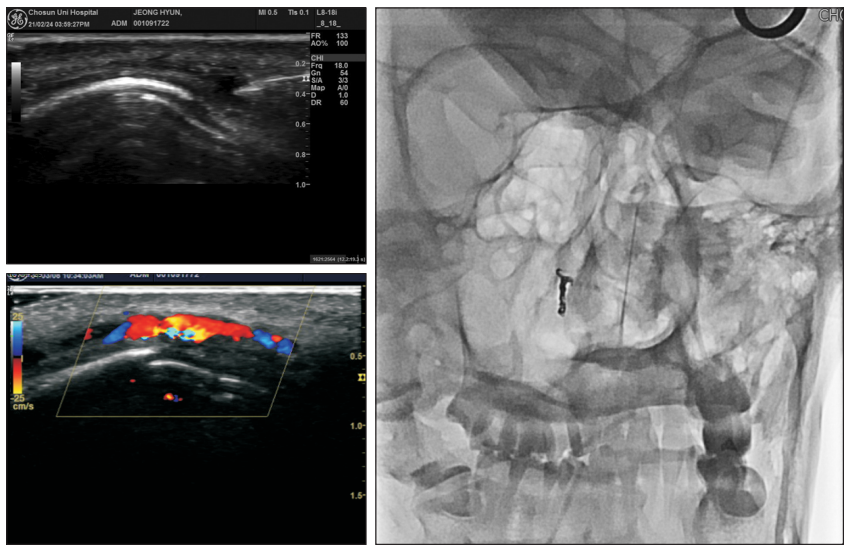

Fig. 6. We blocked the blood reflux to the venous system of the orbit, by compressing the malformation lesion with hand and infused $0.3 \mathrm{cc}$ of $99 \%$ ethanol. On repeating the venogram, no more opacification was observed on the arteriovenous malformation. No further vascular flow was observed on repeat sonography.

The next day, under general anesthesia, local anesthesia was administered at the bilateral septum using $1 \%$ lidocaine mixed with 1:100,000 epinephrine. A modified Killian incision was made using a \#15 scalpel blade and a mucoperichondrial flap was elevated from the septum via the endonasal approach. Correction of septal deviation was performed after removal of the posterior and inferior portions of the septal cartilage and bony septum. A long incision was given on the inferior portion of the inferior turbinate, and mucosal elevation of the medial portion of the inferior turbinate was performed. Partial removal of the bony turbinate and lateral portion of the turbinate's mucosa was performed. Redraping of the turbinate's mucosa was done. After silicone sheet application and nasal packing was done with Merocel.

After 3 weeks, the patient visited the outpatient clinic. We evaluated the paranasal sinuses using computed tomography to confirm arteriovascular malformation on the nasal dorsum. Computed tomography revealed an enhanced lesion in the nasal dorsum. We found that the feeding artery was invisible, but venous drainage from the mass was evident. Therefore, we decided to perform an additional sclerotherapy procedure.

On sonography, we directly punctured the mass and performed a venogram, and found that the veinous drainage was maintained from both the venous system of the orbit and the facial vein. By checking the Doppler waveform and velocity, we confirmed that there was no more arterial flow. Therefore, we blocked the blood reflux from the venous system of the orbit, compressed the lesion with the hand, and infused $0.3 \mathrm{cc}$ of $99 \%$ ethanol. On repeating the venogram, no further opacification on the AVM was observed. Repeat sonography we checked that there was no more vascular flow (Fig. 6).

\section{Discussion}

AVMs are vascular malformations with abnormal capillary shunts between the arterial and venous systems. Usually, AVMs are congenital anomalies; however, in most cases, they are discovered later in life. Differentiation between arteriovascular malformations, hemangioma, and lymphangioma is necessary, and magnetic resonance imaging and angiography are required for accurate diagnosis [4].

Vascular malformations can be classified into capillary, venous, arterial, and lymphatic, and can also be divided into two types according to the blood flow velocity. Capillary, venous, and lymphatic malformations are "low-flow" lesions, whereas arterial and AVMs are "high-flow" [5].

Measuring the density of blood vessels through Doppler ultrasound can also be helpful in diagnosing vascular malformations [3].

Most hemangiomas can be distinguished from AVMs clinically and by physical examination [2]. Hemangiomas are the most common vascular malformation and occur in the head and neck in more than half of the cases [6] but rarely occur in the nose. These are not congenital and rapidly proliferate in endothelial cells [7]. Most hemangiomas do not require treatment, 
but treatment is needed if symptoms are present or if the patient desires. Treatment, including chemotherapy, using highdose steroids, alpha interferon, vincristine, embolization, and surgical treatment, are also possible [3].

AVMs result in increased endothelial turnover. Most AVMs increase in size over time, and in female, the increase in size is because of hormonal influences related to puberty or pregnancy [7]. In general, contrast-enhanced computed tomography and magnetic resonance imaging are performed to determine the size and extent of the mass. On computed tomography, the blood flow in the mass shows contrast enhancement. Magnetic resonance imaging demonstrates the soft tissue extension of the mass. Selective angiography utilizing the subtraction technique is most important for diagnosis $[8,9]$. AVMs are usually not treated when asymptomatic, but treatment is needed if symptoms or complications are present. AVMs can cause vital structural obstructions and can lead to cardiac failure [5].

It is important to consider the cosmetic aspects, especially in cases of facial AVMs. Large-sized AVMs often contain normal structures, making it difficult to treat only with surgical procedures [6].

In this case, paranasal sinus computed tomography showed a lobulated mass with contrast enhancement, approximately 11 $\mathrm{mm}$ in size in the right nasal dorsum, and congested vascular tissues observed around the mass. A hemangioma or an AVM was suspected, and computed tomography angiography was performed to evaluate the mass. Angiography was performed through the right common femoral artery, and angiography of the right external carotid artery showed a mass in the right nasal dorsum region where blood flowed at a high velocity. Blood supply to the lesion was through the branches of the facial artery and right lateral nasal artery. Therefore, it was confirmed that the lesion was closer to a AVM than to a hemangioma. After diagnosis, embolization and sclerotherapy were performed.

Surgical treatment is the simplest option; however, it is associated with a risk of bleeding, and if the lesion is not excised properly during surgery, there is a possibility of recurrence. Furthermore, it is difficult to achieve cosmetic outcomes with surgery. In most cases, preoperative embolization is performed to reduce blood flow before surgical excision. Excision should be performed within 48 to 72 hours after embolization [10-13]. As a complication of embolization, the injection material blocks other blood vessels, and there is a risk of tissue and organ damage. In our case, particle embolization was also performed for the purpose of treatment before sclerotherapy. Sclerotherapy is a method of injecting a sclerosing agent into the AVM and closing the arteriovenous shunt by forming a clot. In general, sclerotherapy using ethanol is the most widely used method [4], and in this case, sclerotherapy was performed using $99 \%$ ethanol. There is no ideal interval between embolization and sclerotherapy.

Most extracranial AVMs require combined treatment, especially when the malformations have an infiltrative component, with multiple feeding arteries. Even in these patients, the percentage of the total response (cure) is low, with high relapse rates. The recurrence rates have been described in the literature (14.2\% and 64.3\%). However, a direct comparison of the results is not adequate, since the procedure used (pathway and embolic material) as well as the definition of complete and partial response is quite variable among various studies [14].

Major complications include blindness because of ophthalmic artery occlusion and external to internal carotid artery anastomosis emboli, resulting in stroke. Minor adverse events include facial pain resulting from ischemia and can be managed with appropriate analgesia. Bradycardia from a trigeminocardiac reflex has been reported to be associated with the manipulation of the external carotid artery branches, which likely involves the afferent tracts of the trigeminal nerve to the vagus nerve [15].

In case of facial tumors, treatment should be performed considering the cosmetic aspect. If there is a mass on the nasal dorsum, as in this case, especially if there are no symptoms, treatment may be performed according to the cosmetic requirements of the patients [6].

In this case, the patient was young and there was no discomfort except nasal obstruction related to the protruding mass on the nasal dorsum; therefore, we considered cosmetic management first. The patient was satisfied with the cosmetic aspect of the treatment for AVM with embolization and sclerotherapy, rather than surgical treatment.

\section{Conflicts of interest}

The authors have nothing to disclose.

\section{References}

1. Rodriguez IE, Khechoyan DY, Deleyiannis FW, French B. Surgical management of a nasal AVM in a pediatric patient: a case report. JPRAS Open 2018;16:93-7.

2. Donnelly LF, Adams DM, Bisset GS 3rd. Vascular malformations and hemangiomas: a practical approach in a multidisci- 
plinary clinic. AJR Am J Roentgenol 2000;174:597-608.

3. Coskun BU, Sozen E, Basak T, Alkan S, Dadas B. Arteriovenous malformation of the nasopharynx: a case report. Int J Pediatr Otorhinolaryngol 2005;69:1287-90.

4. Noh Y, Ryu G, Kim HY. A case of arteriovenous malformation of the nasal tip. Korean J Otorhinolaryngol-Head Neck Surg 2020;63:123-8.

5. Khorasani GA, Rakei S, Riazi H. Massive nasal arteriovenous malformation (AVM) excision and reconstruction with expanded forehead flap: a case report. World J Plast Surg 2017;6:106-10.

6. Weinzweig N, Chin G, Polley J, Charbel F, Shownkeen H, Debrun G. Arteriovenous malformation of the forehead, anterior scalp, and nasal dorsum. Plast Reconstr Surg 2000;105:24339.

7. Mulliken JB, Glowacki J. Hemangiomas and vascular malformations in infants and children: a classification based on endothelial characteristics. Plast Reconstr Surg 1982;69:41222.

8. Luessenhop AJ, Spence WT. Artificial embolization of cerebral arteries. Report of use in a case of arteriovenous malformation. J Am Med Assoc 1960;172:1153-5.

9. Merland JJ, Ricke MC, Hadjean E. The use of superselective arteriography, embolization, and surgery in the current management of cervicocephalic vascular malformations (350 cases). In: Williams HB, editor. Symposium on vascular malformations and melanotic lesions. St. Louis: Mosby; 1983. p. 135-43.

10. Kerber CW. Flow-controlled therapeutic embolization: a physiologic and safe technique. AJR Am J Roentgenol 1980;134:557-61.

11. Schrudde J, Petrovici V. Surgical treatment of giant hemangioma of the facial region after arterial embolization. Plast Reconstr Surg 1981;68:878-89.

12. Azzolini A, Bertani A, Riberti C. Superselective embolization and immediate surgical treatment: our present approach to treatment of large vascular hemangiomas of the face. Ann Plast Surg 1982;9:42-60.

13. Demuth RJ, Miller SH, Keller F. Complications of embolization treatment for problem cavernous hemangiomas. Ann Plast Surg 1984;13:135-44.

14. Lazzaro MA, Badruddin A, Zaidat OO, Darkhabani Z, Pandya DJ, Lynch JR. Endovascular embolization of head and neck tumors. Front Neurol 2011;2:64.

15. Oliveira C, Donato H, da Silva FP, Donato P, Agostinho AG, Carvalheiro V. Long-term outcome of embolization of extracranial arteriovenous malformations of the head and neck. Acta Radiol Port 2015;106:17-22. 